\title{
Guinea-Bissau: Poverty Reduction Strategy Paper- Second Annual Progress Report-Joint Staff Advisory Note
}

This Joint Staff Advisory Note on the Second Annual Progress Report on the Implementation of Guinea-Bissau's National Poverty Reduction Strategy was prepared by the staff teams of the International Monetary Fund and the World Bank as background documentation for the periodic consultation with the member country. It is based on the information available at the time it was completed on November 24, 2010. The views expressed in this document are those of the staff team and do not necessarily reflect the views of the government of Guinea-Bissau or the Executive Board of the IMF.

The policy of publication of staff reports and other documents by the IMF allows for the deletion of market-sensitive information.

Copies of this report are available to the public from

International Monetary Fund • Publication Services

$70019^{\text {th }}$ Street, N.W. • Washington, D.C. 20431

Telephone: (202) 623-7430 • Telefax: (202) 623-7201

E-mail: publications@imf.org Internet: http://www.imf.org

\section{International Monetary Fund Washington, D.C.}


INTERNATIONAL MONETARY FUND

AND

INTERNATIONAL DEVELOPMENT ASSOCIATION

\author{
GUINEA-BISSAU
}

\title{
Joint Staff Advisory Note on the Second Annual Progress Report on the Implementation of the National Poverty Reduction Strategy (NPRS)
}

\author{
Prepared by the Staffs of the International Monetary Fund (IMF) \\ and the International Development Association (IDA) \\ Approved by Roger Nord and Thomas Dorsey (IMF) \\ And Obiageli K. Ezekwesili (IDA)
}

November 24, 2010

\section{OVERVIEW}

1. This Joint Staff Advisory Note (JSAN) reviews progress in the implementation process of the National Poverty Reduction Strategy Paper (NPRSP) over the period July 2009 to July 2010, as reported in the Second Annual Progress Report (APR). The Second APR expands upon and updates the information presented in the First APR on the NPRS prepared by the government in late 2009 to better reflect Guinea-Bissau's more recent and accelerating efforts to accomplish the goals set forth in the NPRSP.

2. While political and economic constraints limited the government's achievements during 2007-2009, the reforms initiated in the second half of 2009, have generated significant and encouraging results. The government has expressed its commitment to utilizing the experience of the first NPRSP and the recent positive outcomes to inform the design of its new strategy paper, the NPRSP II, being prepared.

3. The NPRSP adopted in 2007 was built around four pillars: (i) strengthening governance, modernizing the public administration and ensuring macroeconomic stability; (ii) enhancing economic growth and job creation; (iii) increasing access to social services and basic infrastructure; and (iv) improving the living conditions of vulnerable groups. ${ }^{1}$ A high

\footnotetext{
${ }^{1}$ The process of formulating the first NPRSP began in 2000, when Guinea-Bissau reached the decision point for the Heavily Indebted Poor Country (HIPC) initiative. It continued through 2004, when the government formally adopted a first draft of the NPRSP as a strategic policy document reflective of its long-term development plan (Djitu ten). Further revisions were made in 2004 and 2005 before the NPRSP was presented to the country's development partners in 2006, and after a brief delay due to ongoing political disruptions, effective implementation of the NPRSP's provisions began in 2007. As mentioned by the IMF-IDA JSAN on the PRSP (April 2007), the PRSP was built on grassroots consultations at the national level involving all segments of society. The consultative process included three levels of participation: (i) a political and institutional level, engaging the government and its development partners; (ii) a technical level, engaging
} 
degree of political instability and administrative discontinuity repeatedly delayed the formulation and implementation of the NPRSP and undermined its political ownership; hampered economic growth; and weakened the government's limited capacity to mobilize resources for vital infrastructure improvements, antipoverty programs, and much-needed reforms in fiscal policy and macroeconomic management ${ }^{2}$.

4. Guinea-Bissau's First APR on the NPRSP provides a candid review and analysis of the implementation of NPRSP policies from 2007 to 2009. The First APR acknowledges that overall progress was uneven, though this was not surprising given the continued political instability, rapid succession of administrations, and large-scale turnover of top civil service staff.

5. The Second APR covering the period between July 2009 and July 2010, notes improvements made in the last year while still being candid about the considerable obstacles that remain. Political stability continues to be required for effective reform. Much of the substantive progress on major NPRSP policy areas was achieved during a period of relative peace, stability and security. Despite ongoing security concerns, a climate of renewed stability and cautious optimism continues to hold sway. Much of the progress achieved since mid-2009 has been under the first two pillars. In particular, several successful measures to improve public financial management and the business climate were initiated or accelerated during 2009-2010. On the commitment to, and strength of, these efforts, the IMF approved a 3-year arrangement under the Extended Credit Facility (ECF) for 2010-2012, while the World Bank approved a series of two Economic Governance Reform Grants in 2009 and 2010.

\section{Poverty Reduction}

6. An assessment of trends in poverty remains sharply limited by the lack of data. Since the first poverty assessment survey (Inquêrito Ligeiro de Avaliação da Pobreza, ILAP I) performed in 2002 no new income or expenditure poverty data has been produced. The government's Statistical Institute undertook a new poverty survey (ILAP II) in July 2010 whose results are expected to be available by the end of 2010 .

7. However, preliminary results from a recent survey show positive recent developments in the social sectors. Updated information obtained from the Multiple Indicators Cluster Survey (MICS) conducted in July 2010, with indicators on education, health, gender equality and HIV, indicates that the country has made progress on most indicators. The MICS is the third of its kind in the decade, following previous surveys in 2000 and 2006, and it is therefore possible to assess trends in these social indicators. A more elaborated assessment of poverty is expected from the new poverty survey ILAP II. Overall, there has been strong progress on most of the MICS indicators. In education, school enrollment rates grew from 42 percent in 2000 to 45 percent in 2006 and to 65 percent in 2010. A similar trend is observed in gender equality in education, with converging school enrollment rates: the ratio

national public and private sector leaders as well as civil society leaders; and (iii) a popular and community level based on consultations with stakeholders in rural and urban areas.

${ }^{2}$ Modest economic growth rates together with the government low domestic revenue mobilization and uncertain international financial support resulted in lower than projected resource availability for the NPRSP. 
of girls' to boys' enrollment grew from 0.67 in 2002 to 0.83 in 2006 and to 0.94 in 2010. In parallel to the acceleration in the school enrollment of girls there was a rapid reduction of illiteracy rates in young women (15 to 24 years) from 83 percent in 2000 to 72 percent in 2006 and to 61 percent in 2010 . Of course, while the broader coverage of education is highly positive, the country continues to face challenges on the quality of public education services which remains weak.

8. On health, results are impressive. Under five child mortality, which had increased from 203 deaths per 1000 births in 2000 to 223 in 2006, fell to 155 in 2010. Infant mortality followed the same pattern, increasing from 124 deaths per 1000 births in 2000 to 138 in 2006 and to 104 in 2010. While these positive developments cannot be attributed to any single government-controlled factor-with contributions from NGOs or the private sector and demand-side developments also underpinning improvements in social indicators - they show that, at the very least, the policy and administrative environment has become more supportive of progress on the social front ${ }^{3}$.

\section{Progress on Individual Pillars}

\section{Pillar I: Strengthening Governance, Modernizing the Public Sector, and Promoting Macroeconomic Stability}

9. The primary objective of this pillar is to establish the necessary conditions for the effective and full application of the rule of law and ensure the responsible and efficient operation of public agencies and processes. This includes adopting appropriate legislative measures to strengthen judicial institutions and reinforce the integrity of government operations, implementing structural reforms in the public administration to improve the efficiency of the public sector, and developing sound macroeconomic policies to encourage prudent fiscal management and promote the sustainability of the public debt.

10. In spite of adverse global market conditions and continuing challenges on the domestic political and macroeconomic policy fronts, the government has been able to make significant progress on the NPRSP's public sector reform agenda, including enhancing governance and promoting macroeconomic stability.

\section{Macroeconomic stability}

11. Improved macroeconomic management has helped the country weather the effects of the global financial crisis relatively well. The negative impacts of the crisis were transmitted mainly through declines in export values and remittances, both of which impacted domestic demand at a time when the space for fiscal stimulus was sharply limited. Export prices for cashew, by far the country's most important source of export earnings, fell by almost 30 percent between 2008 and 2009. The total loss in terms of trade reached 22 percent, which exerted a strongly negative impact on the external current account and government revenue.

\footnotetext{
${ }^{3}$ Despite the recent improvements in health, Guinea-Bissau indicators remain well below the regional averages and out of reach of the MDGs, therefore the progress acceleration observed in 2009-10, could be interpreted as a catching up movement towards regional levels.
} 
However, the total value of exports only declined by about 7 percent due to a sizeable increase in export volumes as a result of the ongoing liberalization of the agricultural sector combined with efforts to increase producers' access to capital. In 2010, a strong rebound in the terms of trade is contributing to helping stabilize growth, while reducing the balance of payments and fiscal pressures.

12. Fiscal performance remained satisfactory despite both the deterioration of global market conditions and delays in the disbursement of external budget support. By exercising strict control over expenses (mainly government consumption and domestically financed capital spending) and improving revenue collection, the government was able to improve its fiscal balances and stabilize debt levels. To help strengthen expenditure control, the government also implemented norms that helped tighten the recourse to simplified spending procedures, which allowed the government to keep non-regularized expenditures at a low level. The treasury committee, which became operational in 2010, was an effective tool in improving cash management.

13. This renewed commitment to responsible fiscal management helped strengthened macro stability. It enabled the government to be current on wage payments and to start paying arrears to the private sector. As a result, private-sector confidence improved, and the fiscal impulse helped sustain the country's economic growth rate in the face of worsening external conditions. As the Second APR indicates, the recovery of cashew prices and the steady pace of government spending could further increase economic growth to about 4 percent in 2010 .

\section{Public sector reform}

14. Drawing in part on the Public Expenditure Management and Financial Accountability Review (PEMFAR), prepared jointly with the African Development Bank (AfDB), the EU and the World Bank in 2009, the government has taken decisive steps to improve public finance management, enhance the efficiency of government procurement, and restructure the civil service. In this regard, the authorities approved the Organic Framework of the State Budget and complementary legislation regulating the role of the different government entities responsible for budget formulation and execution. The Integrated System for Public Financial Management (SIGFIP) for the register and control of government budget preparation and execution transactions was extended to the treasury, and customs upgraded its computerized customs management system which covers most foreign trade procedures (ASYCUDA++).

15. The government installed the Integrated Debt Management Financial and Analysis System (SYGADE) in the third quarter of 2009 to improve the systematic electronic recording of data; however, it is not yet in use. However, there are still shortcomings in debt management associated with capacity constraints. Under the ECF, the government is committed to address these shortcomings and develop and pursue a prudent debt management strategy. The government plans to strengthen the unit of public debt management and start producing quarterly reports on public debt, using SYGADE to record and manage all public debt. 
16. In public procurement, the authorities adopted far reaching reforms, effectively leapfrogging to the standards and institutions of their faster reforming neighbors. The government approved a new Public Procurement Law in June 2010 to harmonize procedures with the standards of the West Africa Economic and Monetary Union (WAEMU), and it passed additional measures to strengthen enforcement of the code and facilitate monitoring of procurement transactions. The new system also creates a Procurement Regulatory Authority (ARCP) with external oversight responsibilities, as well as a Central Procurement Unit (UCP) that should replace individual procurement units for line ministries.

17. Progress has also been made in public administration reform and human resource management. In this area the government completed a biometric census of all public sector staff at the end of 2009, with the objective to reduce the weight of personnel expenses, which currently still represent more than 70 percent of current revenues - though from a high of over 120 three years ago- - and to rationalize the deployment of the civil service. The results provided an accurate account of public sector employees as well as identified "double dippers" (officials holding multiple posts) and "ghost workers" (individuals receiving unearned salaries). The government is following through with initiatives designed to increase the government's administrative capacity. In particular, the existing Center for Administrative Training has begun to be reorganized into a new National School of Public Administration dedicated to providing more targeted and specialized education to new and prospective public sector employees.

18. Despite the enormous challenges facing the defense and security sector reform, the government undertook several important actions demonstrating its commitment to the resolution of this critical and highly contentious issue. In January 2010 it formally adopted the Reform of the Defense and Security Sector (PPRSDS) program, mandating a reduction in the size of the country's military forces, the creation of a pension fund for retired soldiers and officers, transitional programs for demobilized personnel reentering civilian life, and new programs to enhance the professionalism of military personnel. In addition, the National Assembly (ANP) approved ten decrees governing the structural reorganization of the Armed Forces. Among them, the Law of National Defense and Armed Forces, the Organic Law of the Armed Forces, the Reform Program for the Military Justice System, the Organic Law of the Public Order Police Force, and the Organic Law of the National Guard constitute landmark achievements in national defense and security sector reform. The government will need to work closely with donors to put these reforms into operation and to implement the needed streamlining of the armed forces. In addition, a stable political environment will be a necessary condition.

19. The APR underscores the political, administrative and financial ambition of security sector reform, but notes that the government has already taken some implementation steps. The reform itself has been put squarely on the public agenda. In June 2010 the government organized the International Conference for the Reform of the Defense and Security Sector with the participation of all sectoral institutions, as well as a number of civil society organizations and representatives of the international community, which culminated with the signing of the Declaration of Bissau. At a more operational level, the government has also initiated the rehabilitation of several military installations where the poor living conditions of soldiers had become a persistent source of grievance, provided capacity building activities 
for the Public Order Police Force, and installed a Computerized Training Center for agents dedicated to internal security and criminal investigation.

\section{Pillar II: Economic Growth and Job Creation}

20. The objective of the second NPRSP pillar is to enhance conditions for economic growth through the improvement of business environment, the provision of economic infrastructure, and the promotion of productive sectors with large impacts on employment creation and poverty reduction.

21. In the face of severe and protracted financial and capacity constraints, the government has made little progress in the expansion and rehabilitation of economic infrastructure, and the performance of the energy, seaport and road transportation sectors continues to constrain economic growth. In the energy sector, the government's actions concentrated on improving the transmission and generation capacity of the national electric utility. In 2010 the government completed the rehabilitation of the electricity network initiated in 2008, installed power generators in Farim $(50 \mathrm{KW})$, Cacheu $(350 \mathrm{KW})$ and Canchungo $(500 \mathrm{KW})$, initiated a restructuring plan for the Electricity and Water Company (EAGB) and obtained funding from the World Bank, the WAEMU and the Economic Community of West African Countries (ECOWAS) amounting to US\$23 million to increase generating capacity in Bissau and to supply working capital to EAGB. The government has also initiated the reform process of EAGB, which is aimed at attracting private sector participation.

22. The government has achieved an important improvement in road transportation with the completion of the EUROAFRICANA Bridge at the Cacheu River in São Vicente. This bridge is expected to facilitate increased trade between Senegal and Guinea-Bissau. Despite the precarious situation of the port of Bissau, the government was not able to resolve its major operational and institutional problems and made only modest investments in new equipment.

23. However, while recognizing that progress on this pillar has been uneven, the APR update highlights the acceleration of the reform agenda directed at improving the business environment, including reducing bureaucratic and transaction costs. In December 2009, the President promulgated a new investment code consistent with international good practices and WAEMU regulations. The government approved a new public-private partnership law aimed at exploring new ways to finance public investment projects and foster private initiative in the provision of public services. The ANP also approved the Telecommunications Law, which establishes a revised regulatory framework for telecommunications and ensures a level playing field for private investors in a sector that has expanded rapidly in recent years.

24. The government has also taken important steps to simplify business opening and closing procedures. In April 2010 it adopted a decree simplifying procedures for business registration, significantly reducing the number of administrative steps needed in these processes, and it also passed a decree formally mandating the establishment of a one-stop shop for business registration. The government expects that these improvements in the investment climate will support more rapid private-sector-led growth and boost job creation. 


\section{Pillar III: Improving Access to Social Services}

25. Broader access to social services contributed to the strong improvement in education and health indicators. The elimination of school fees a few years ago, and the introduction of school feeding program in most of primary schools had an impressive positive impact on enrollment rates, especially on girls' enrollment in rural areas. Recent massive vaccinations campaigns, effective distribution of bed nets and improvements in health facilities had also positive effects on the reduction of infant mortality, improvements in maternity health and public health service centers coverage.

26. Since 2009 the government has made dramatic strides in education reform to improve the quality of educational services, combining long-term strategic planning with specific legislation targeting individual aspects of the education system. The government's guiding policy document for the education sector, the Educational Policy Charter, was adopted by the Cabinet in 2009. It describes the government's objectives for the sector over the coming decade (2010-2020) and provides a broader strategic context for the draft of new legislation passed since 2008. The Education Law, passed in March of 2010, details a set of mediumterm sector-wide mandates, expanding compulsory education to cover secondary schooling as well as primary and lowering the minimum age of enrollment from 7 years to 6 .

27. On the health sector, the government has prepared a new, long-term strategy for the public health sector, the National Health Development Policy, which was approved in May 2010 and extends from 2011 through 2017, and a broader policy framework for the entire decade is nearing completion. The report lacks a detailed account of the plan, but describes a number of concrete steps that have already been taken to improve health services. Recognizing a persistent shortfall in available staff, 115 new healthcare professionals were assigned to facilities around the country; an incentive premium for healthcare workers operating in isolated rural areas, retroactive to 2009, has been paid in full, and these incentives have been formally incorporated into the pay scale. In 2009, the government completed the construction of four new health centers, as well as rehabilitated and reequipped two hospitals, expanded the national hospital in Bissau, and renovated the Motor Bra rehabilitation clinic and appointed new management.

28. Efforts to improve antenatal care, vaccination access, micronutrient distribution, and blood-donor screening all accelerated during 2010, and while the report lists the most recent statistics recorded, due to previous lapses in data collection little information is available on the relative progress made in these areas. The same is true for malaria and typhoid incidence, as well as clean water and sanitation access: numerous initiatives have begun or are ongoing, and current indicators are apparently positive, but without time-series data and other contextual information it is difficult to gauge accurately the extent of the progress made in these areas.

29. There has been, however, demonstrable progress on the part of the administration on two key health priorities, namely combating cholera outbreaks and the spread of HIV/AIDS. Thanks to a concerted awareness and prevention program by the national health authorities and their partners in the NGO sector no new cholera epidemics occurred during 2009 and 2010. The government's HIV/AIDS strategy is more complex: recognizing the pervasive deficiencies in reliable program data and analysis the government established a Technical 
Committee on Monitoring and Evaluation dedicated to HIV/AIDS programming. It has also formed a National Forum on HIV, and a government website providing information and resources is now operational. The government has signed a sophisticated set of partnerships, including funding agreements, with local institutions, civil society groups, and private-sector firms. 22 counseling and voluntary testing centers are currently operational, with 10 more under development, and the number of treatment centers more than doubled between 2008 and 2009, from 12 to 26 operational facilities. The most recent data also indicates increasing public awareness of the nature and transmission vectors of HIV, which are likely the combined effect of health sector programs and the introduction of new educational curricula on HIV/AIDS in public schools.

\section{Pillar IV: Enhancing the Living Conditions of Vulnerable Groups}

30. Government actions targeted to improve the welfare of vulnerable groups have been concentrated on gender and youth areas. In addition to efforts to improve girls' school enrollment rates, key actions undertaken in 2009 and 2010 towards promoting gender equality centered on drafting proposed legal texts on reproductive health, violence against women and girls; and trafficking in persons.

31. In the area of child protection and the safeguarding of children's rights, efforts were made to strengthen a number of policies and strategies: (i) the National Committee to Eliminate Female Genital Mutilation was reestablished, as an important body to coordinate work in this area; (ii) in Gabú and Bafatá shelters for children who are victims of violence have been rehabilitated and are now being fitted out; and (iii) the second report on the implementation of the United Nations Convention on the Rights of the Child (CRC) has been

presented to the Committee on the Rights of the Child in Geneva, together with an alternative report by NGOs.

\section{IMPLEMENTATION, MONITORING, AND EVALUATION}

32. The overall assessment of the implementation period indicates that because of its overly optimistic assumptions the NPRSP presented an agenda that was impractically ambitious and lacked both a clear definition of priorities and a results-oriented framework. These design flaws were compounded by political instability, pervasive weaknesses in technical and institutional capacity, financial constraints, and inconsistent coordination among government entities and with international partners. As a result, progress in the first years of NPRSP implementation was highly uneven. By 2009-2010, however, the improved consistency and heightened coordination of government actions guided a more focused and pragmatic reform program and allowed an acceleration of NPRSP implementation. This said, given the continued constraints on fiscal resources and capacity expected to prevail in the coming years, the government recognizes the need for a more targeted and efficient strategy for fostering economic growth and reducing poverty. In addition, the government has acknowledged the crucial importance of adopting a results-based orientation to increase public accountability and program effectiveness.

33. The APR highlights the lack of effective monitoring and evaluation systems as a major obstacle to achieving the goals of the original NPRSP. The NPRSP encompassed a 
monitoring and evaluation mechanism consisting in the Implementation and Monitoring Unit (CISD) led by the Ministry of Economy, Planning and Regional Integration (MEPIR) and a decision-making steering committee chaired by the Prime Minister's office. However, for a number of reasons this system has not been operational. First, the NPRSP did not include a set of precise results indicators that could be measured periodically. Second, weak technical capacity at the (CISD) and line ministries prevented the generation and circulation of information necessary to monitor progress in program execution. Third, while the NPRSP proposed an institutional framework for monitoring and evaluation, the roles and responsibilities of the various agencies were not defined, and there was no technical support provided to them. Fourth, the government's unresolved lack of statistical capacity became a binding constraint on monitoring and evaluation.

34. The staffs therefore commend recent government efforts to improve its monitoring and evaluation systems. In 2009, with the support of the United Nations Development Program (UNDP) and the African Development Bank (AfDB), the government initiated a capacity-building project to develop the monitoring and evaluation framework that will be used for the NPRSP II. This is a two-year program with funding of about US\$4 million and includes technical assistance to make the NPRSP and the Millennium Development Goals (MDGs) monitoring and evaluation mechanisms operational, as well as support for the management of information systems and results-oriented budget planning. The project also involves training activities to be coordinated by the CISD, a capacity-building program for the National Institute of Statistics (INE), and financial support for statistical activities and the implementation of national surveys. INE has also completed the diagnostic of the national statistical system (NSS) during the period under review. NSDS is the first step to strengthen GB NSS and to ensure a production of quality data, more coherent, comparable and relevant to the NPRSP.

\section{RISKS AND CONCLUSIONS}

35. The Second APR gives a fair assessment of the recent progress achieved and challenges encountered in implementing the NPRSP. The reports identify correctly the intrinsic and contextual factors that impacted NPRS implementation and also provide important lessons that should serve as the basis for the preparation of the NPRSP II. The Second APR however, would benefit from more clearly linking government actions and the positive results in social areas obtained in 2009-10.

36. Much progress has been achieved since mid-2009. Preliminary results from the recent MICS shows that the country has made progress in social indicators. The authorities have made progress in several of the pillars of the first NPRSP. With respect to Pillar I, the macroeconomic situation stabilized despite unfavorable external and domestic political environments; several public sector reform measures have been implemented to improve public financial management, such as a revamped treasury monitoring, a computerized customs management system, the census of all public sector employees, and enabling steps for the reform of the security and defense sectors; and in the area of governance, several laws improving the procurement system have been passed. Much has been achieved under Pillar II: a new investment code has been approved, as well as a new public-private partnership law and the telecommunication law; and the government adopted a decree establishing a one-stop 
shop. However, due to capacity and financial constraints little progress has been made in the expansion and rehabilitation in the areas of infrastructure, energy, ports, and transportation. Some progress has been made improving access to social services (Pillar III) such as the strong increase in enrollment rates, and the improvement of health indicators. The improvement of girls' enrollment rates and the approval of legislation protecting women and children are the most significant achievements under Pillar IV.

37. The most important risk continues to be the threat of political instability. This has been the most important factor in Guinea-Bissau's development over the past decade, hindering economic growth and undermining the implementation of the NPRSP. Political instability has repeatedly compromised the maintenance of law and order as well as the ability of successive governments to provide essential public goods and services. It has further damaged already weak institutions, and contributed to high turnover in senior positions and to the exodus of qualified personnel from the public sector. Political discontinuity has also weakened government ownership of the NPRSP process and promoted inconsistency in government actions. In 2009-2010 a more stable political environment and the new government have enabled the acceleration of the NPRSP agenda. Nevertheless, the incidents of April 1, 2010, when the Prime Minister and head of the army were arrested by the second-in-command of the army and recent appointments in the armed forces ${ }^{4}$, demonstrated that the political and military situation remains fragile and the difficulties still faced by the reform agenda in this area. In this context, the continued support of the international community during its political transition seems to have been a key factor in shoring up stability.

38. Ongoing support from development partners continues to be critical for adequate implementation of public policies. Low technical and institutional capacity has complicated the design and implementation of public policies in general and the NPRSP in particular and continues to be a risk for the implementation of the NPRSP II. To reduce risks associated with technical and institutional limitations, capacity-building activities are being undertaken covering cross-cutting areas such as monitoring and evaluation, strategic planning, project management, and statistical analysis.

39. On the macroeconomic front, the impact of the global financial crisis and a slowerthan-expected recovery from its effects could undermine the country's already challenging stabilization efforts, which rely heavily on high and sustained donor support. Insufficient and uncertain funding remains a major risk to the effective implementation of the NPRSP II, and it will be critical for Guinea-Bissau's development partners to reaffirm their commitment to financing the country's new economic growth and poverty reduction strategy.

40. Several lessons can be drawn from the NPRSP implementation in Guinea-Bissau. The NPRSP was too ambitious, broad and not focused, and it did not have a result framework to monitor implementation and results. These shortcomings in the design were aggravated by the lack of continuity in government due to political instability leading to high turnover of administration and technical staff, and hampered NPRSP implementation before 2009.

\footnotetext{
${ }^{4}$ The Prime Minister was promptly released; the head of the army remained under arrest, and, in July 2011, was officially replaced in his position by the former second-in-command.
} 
Associated with high turnover in administration, ownership was weak as administrations did not own the NPRSP prepared by other administrations. Recently, NPRSP implementation improved with more consistency in government, while the country began moving toward more political stability. Benefitting from better economic performance, the government managed to mobilize more resources and achieve a more predictable flow of resources, which helped with the recent successes in NPRSP implementation.

41. The NPRSP has become a key point of reference for government actions and coordination of donors' support. It continues to represent the government's medium-term strategy for strengthening governance, promoting economic growth and reducing poverty. Although progress in the early years of the NPRSP failed to meet expectations, accelerated efforts since mid-2009 have yielded significant results and demonstrated the commitment of the current administration to the objectives of the strategy. For the second NPRSP, the staffs are of the view that the government is taking appropriate measures to ensure the enhancement of implementation effectiveness. The need for a more focused strategy and a result-based managerial implementation model and the effective operation of a monitoring and evaluation (M\&E) system are areas which could lead to better results in the second NPRSP. An enhanced harmonization of international support and a more predictable flow of resources are also necessary conditions for a better implementation of the NPRSP. The government has shown a remarkable willingness to frankly and openly assess the challenges it faces and to incorporate the experience of the NPRSP, both positive and negative, into future development planning.

\section{ISSUES FOR DISCUSSION}

42. Directors might wish to focus on the following issues:

- Do Executive Directors agree with the staffs' assessment that the Guinea Bissau authorities have made reasonable progress in implementing the NPRS under the difficult circumstances they faced?

- $\quad$ Do they agree that government is taking appropriate actions to improve implementation in the second NRPS? 